\title{
Attempts to manipulate direct fluorescent antibody test for detection of rabies virus antigen in mouse brain
}

\author{
Imad Ibrahim Al-Sultan \\ Fawzia J. Shalsh \\ Faculty of Medicine / Lincoln University College /Malaysia \\ Ministry Science and Technology / Baghdad - Iraq \\ College of Veterinary Medicine / University of Baghdad / Baghdad - Iraq \\ Faculty of Veterinary Medicine / University Malaysia Kelantan \\ Corresponding author: emanhy.taee@covm.uobaghdad.edu.iq \\ Received: 10 /Aug. /2021, Accepted: 29/Aug. /2021
}

Eman H. Al-Taee

Abdulrahman Aziz

\section{Abstract}

Direct Fluorescent Antibody (DFA) Test for detection of rabies antigen was carried out with attempts in manipulating the standard protocols based on The World Organization for Animal Health (OIE). This study was aimed to achieve improvements of a more rapid detection by conducting modification that could help in reducing the time consume, and costs for obtaining results. The main purpose of this study is to modify the routine protocols for rapid viral detection of rabies virus in tissue. The manipulation that had been practiced was mainly on the fixation procedure with high grade cold acetone, temperature and time of incubation. The working dilution of the fluorescein is thiocyanate (FITC) was (10-1, 10-2, 10-3). Experimental trial on brain samples from 10 rats were obtained and spiked with highest concentration of rabies vaccine for the study. The staining intensity result was analyzed and calculated using $T$-test. The results indicate a variety of intensity for staining and grading of the fluorescent based of the manipulated protocol conducted.

Keywords: Direct Fluorescent Antibody Test, rabies, fluorescent staining grading.

\section{Introduction}

Rabies is an acute viral zoonotic illness that affects the central nervous systems of animals and people all over the world (1) Since 2300 BC, when Louis Pasteur discovered the virus as the source of the sickness, it has been one of the longest recognized infectious diseases in human history (2,3) A neurotropic virus of the genus Lyssavirus of the family Rhabdoviridae causes the illness (4). The virus is made up of five genes: nucleoprotein $(\mathrm{N})$, glycoprotein $(\mathrm{G})$, matrix protein $(\mathrm{M})$, phosphoprotein $(\mathrm{P})$, and viral RNA polymerase (L). The glycoprotein (G) and nucleoprotein (NP) are the most significant proteins $(\mathrm{N})$. The glycoprotein is found in virions' projections and activates neutralizing antibodies, whereas the nucleoproteins are a collection of particular antigens (5). Rhabdovirus with a negative staining, as observed through an electron microscope. Take note of the virus's bullet form (A). See the RNP's "bee hive"-like striations (B). The glycoprotein spikes in the outer member bilayer should be noted (C) Figure (1).

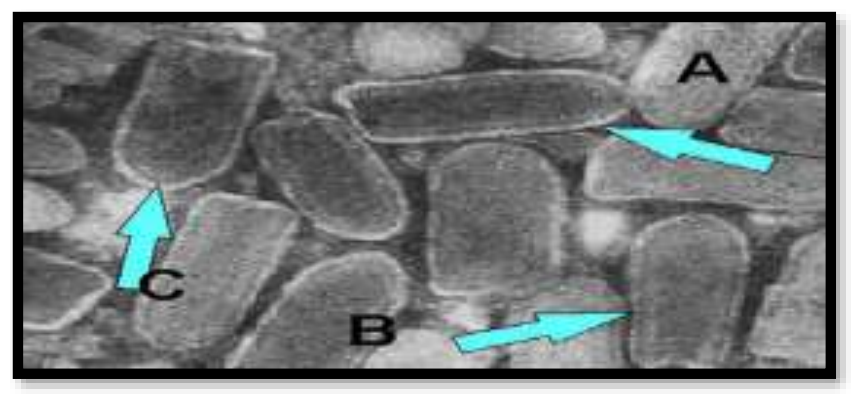

Figure 1: Rhabdovirus on electron microscope. (A) Shows bullet shaped virus, (B) bee hive like striations. (C) Glycoprotein spikes (5)

Lyssavirus type 1 is the most common rabies virus, although there are six additional rabiesrelated viruses as well. Lagos bat virus (type 2), Makola virus (type 3), European Bat Lyssavirus 1 and 2 (types 5 and 6), Duvenhage virus (type 4) and Australian Bat Lyssavirus (type 7) are the different types of bat viruses (7). Rabies has become a public health problem in Malaysia as a 
result of occasional disease importation from Thailand by infected dogs crossing the Malaysian-Thailand border $(8,9)$.

In Malaysia, dogs appear to be the main reservoir of rabies infection, with wildlife serving as a minor reservoir (10). Rabies illness is one of the numerous zoonotic diseases mentioned in the World Organization for Animal Health (OIE) Terrestrial Animal Health Code, and all instances should be reported to the OIE Terrestrial Animal Health Code in order to guarantee public health safety (11). Rabies epidemiology is complicated, as it varies by continent and nation, depending on fauna, environmental variables, and economic development. Rabies is most often found in Asia and Africa's third world countries, where there is a large population of stray dogs that serve as viral reservoirs, with more than 30000 human cases per year (12). As a result, it's been assumed that there were more unreported cases in Asia and Africa (7). The virus is mainly prevalent in the saliva and brain of infected animals, most often in dogs, therefore bites are the most common mode of transmission (13). In contrast to the incubation time for rabies, which is thought to be weeks to six months, the infective phase for dogs and cats is thought to begin ten days before the beginning of the major clinical symptoms. Rabies is deadly in both animals and humans once symptoms appear $(14,15)$.

In terms of pathogenesis, the brain is the virus's primary target organ. The virus will begin to reproduce at the site of infection and attach to nicotinic acetylcholine (NAC) receptors at peripheral nerve terminals to enter and disseminate from the point of entry, which is through bite wounds $(7,2)$. There is no indication of a hematogenous mode of transmission or dissemination. It will then go through the spinal cords to the brain. The virus will move through the CNS again, this time anterograde and retrograde, altering the temperament of infected animals, causing them to become angry or dumb/paralytic (16). There are several techniques for detecting rabies, including the utilization of central nervous system tissues, which are identified using the gold standard fluorescent antibody test (FAT), which is widely used and authorized by both the WHO and the $(17,18,19)$. Others include the mouse inoculation test (MIT), in which substances such as CSF and saliva are injected into mice under specified circumstances, monitored for 30 days, and verified by brain extraction (17). In addition, throughout the years, direct Rapid Immunohistochemical Test (dRIT), immunochromatography, RT-PCR procedures, Rapid Latex Agglutination Test, and ELISA have been employed to help in the diagnosis of rabies $(20,5)$.The findings of the test employing immunofluorescence technique on fresh brain smears indicated evidence of the rabies virus nucleoprotein antigen, which is the most widely used and most accurate method of Direct Fluorescent Antibody Test (FAT) (N). However, because the diagnostic test takes a long time to provide a result, some aspects of the test management must be improved in order to achieve a faster result of the infected animal or human so that treatment and preventative control measures may be implemented. The DFAT is known to be sensitive, specific, and inexpensive, although its sensitivity is dependent on the degree of autolysis in the material and how thoroughly the brain sample is collected (21). The procedures The kind of Lyssavirus and the competence of the diagnostic procedure also influence sensitivity and specificity (17,22).After the DFAT specimens have been washed, glycerol-preserved can be applied. FAT may only be used on specimens preserved in formalin solution after they have been treated with a proteolytic enzyme (23). The DFAT fixed with formalin and digested samples, on the other hand, are usually less consistent and time-consuming than those done on fresh tissue (24). If the results of DFAT are unsatisfactory, it is advised that further tests be performed on the same material or that the FAT be repeated. It's crucial to figure out whether the sample has confirmed or suspected autolysis, which might throw off the findings or test.

The goal of this study was to investigate whether there was a way to enhance and alter the Fluorescent Antibody Test (FAT) protocols to assure a more reliable detection, as well as manipulate or adjust the components utilized in the standard test for a better outcome and faster detection findings.Modifications that may aid in lowering the amount of time and money spent on getting

outcomes. 


\section{Materials and methods}

Sampling and data collection

Approximately 10 rat brain samples were obtained and collected accordingly as the brain sampling collection was done by opening the skull of the rat and gentle removal of the brain. The location of the study was conducted in the Faculty of Veterinary Medicine - University Malaysia Kelantan that had been conducted from March up till May 2016.

Identification of rabies virus antigen

Direct Fluorescent antibody Test (DFAT)

Antisera and conjugates

The Anti-rabies fluorescent conjugates are available commercially either polyclonal or monoclonal antibodies (MAbs) which is specific to the whole virus or to the rabies nucleocapsid protein, conjugated to a fluorophore such as fluorescein isothiocyanate (FITC) (24). The conjugate of $25 \mu \mathrm{g}$ was diluted to $500 \mu \mathrm{L}$ as a working stock and diluted again to obtain working dilution. $\left(10^{-1}, 10^{-2}, 10^{-3}\right)$ was the working dilution for the conjugate by using $60 \mu \mathrm{l}$ of stock added with 540 $\mu$ PBS and diluted accordingly to the concentration markers. Each working dilution was then placed in $-4^{\circ} \mathrm{C}$ refrigerator and used within a week. Fresh dilution was made each week until samples were stained. Working stock was kept in $-20^{\circ} \mathrm{C}$.

\section{Microscopic equipment}

Examination of the FAT slides require specific usage of fluorescent microscope with appropriate filter in order to obtain sufficient wavelength of the fluorescent conjugate to be used. The wavelength is excited at $490 \mathrm{~nm}$ and reemits at $510 \mathrm{~nm}$. The nucleocapsid protein aggregates was examined and identified by the specific fluorescence of bound conjugates (24).

\section{Direct Fluorescent antibody test methodology Slide preparation}

The glass slides were cleaned and degrease with

\section{Reading}

Both control and specimen slides were observed using fluorescent filter microscope within 2 hours two circles of approximately $1 \mathrm{~cm}$ in diameter was drawn on the labelled slide for smear area.

\section{Specimen preparation}

The brain material tissue collected and added killed rabies vaccine to enable presence of antigen in the samples. One vial of the rabies vaccine contains $10^{4} / 1 \mathrm{ml}$ virus and the preparation of brain sample were done by mixing the brain tissue samples with vaccine. One hundred microliters of vaccine were spiked into $1000 \mathrm{mg}$ of brain sample which made the concentration of virus $10^{4} / 1 \mathrm{mg}$ brain sample. The samples were then lightly pressed on the slide using wooden tongue depressor and dried with absorbent papers. Positive and negative controls were also prepared and included in each staining session. On days the specimen is unable to be examined, it is stored in freezer $\left(-20^{\circ} \mathrm{C}\right)$ and unstained (24).

\section{Acetone fixation}

After smearing the samples on the slides, the slides were air-dried thoroughly and a $100 \%$ high grade cold acetone was used. The smears were placed in containers containing cold acetone fully submerge the slides in the container and placed in $-20^{\circ} \mathrm{C}$ for 2,5 and 10 minutes respectively (24).

\section{Conjugate FITC staining}

Slides are removed from acetone and air-dried to reach room temperature. Working dilution of the conjugate prepared were added and layered onto each area of the smears and placed in the incubator at $39^{\circ} \mathrm{C}$ for 10 and 15 minutes. PBS of $\mathrm{pH} 7.2$ to 7.4 is measured and maintains which used to rinse the slides and thorough draining was done to ensure excess stains washed off. A drop of mounting medium 50\% glycerol. Prepared was placed onto the smears and slides were arranged for reading.

to obtained accurate results. Findings of staining intensity and amount of antigen present was conducted by grading from +4 to +1 (Table 1 ). 
Table 1: Direct Fluorescent Antibody Test (DFA) staining intensity grading (25)

\begin{tabular}{cl}
\hline Staining intensity & \multicolumn{1}{c}{ Description } \\
\hline+4 & $\begin{array}{l}\text { High glare, apple green brilliance, abundant antigen in every field and } \\
\text { not possible to count amount per field. }\end{array}$ \\
+3 & $\begin{array}{l}\text { Staining intensity slightly diminished, less glare, abundant antigen } \\
\text { with one or more particles per field and able to count }\end{array}$ \\
+2 & $\begin{array}{l}\text { Dull stain with scanty antigen with one or more particles in few than } \\
100 \% \text { field but more in } 50 \% \text { field }\end{array}$ \\
& $\begin{array}{l}\text { Noticeably dull stain, antigen very scanty, one or more particles in } \\
\text { fewer than 50\% of microscope fields } \\
\text { No presence of antigen throughout whole smear/field }\end{array}$ \\
\hline
\end{tabular}

\section{Statistical analysis}

The results analyzed by using Linear Model General by SAS ready program to study the effect of factors according to complete random design (CRD) also Duncan test was done to defining the significant differences between means of effected factors on parameters at levels $\mathrm{P}<0.05$.

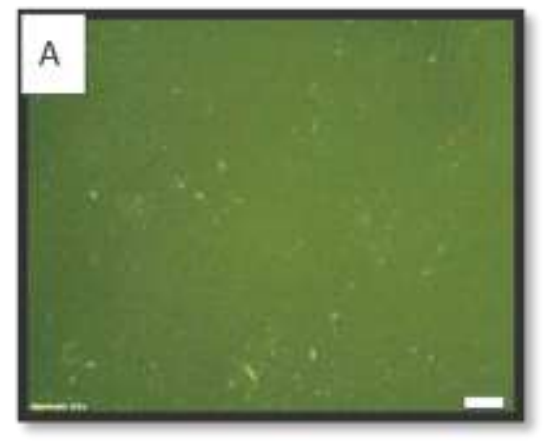

Figure 2: Impression smear of brain tissue showing positive result for FAT.

A-positive result, B-positive result

The effect of fixation and incubation time modification showed positive outcome (Figures 3 and 4) of detecting virus antigen with complete correlation with the standard DFA protocol as in OIE observation showed large oval to small dust like particles within the samples smear areas. Through the rapid modification method, the intensity of the stain and amount of antigen detected were lower than the standard method (Fig. 3 and 4)

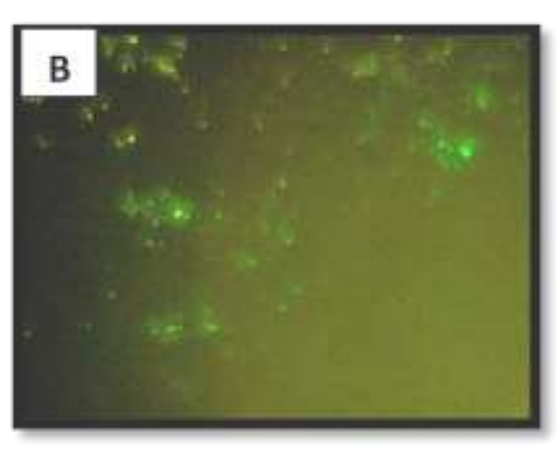

\section{Results}

The impression (smears) slides examined under fluorescence microscope were evaluated on the basis of fluorescence intensity of rabies virus. The results revealed a positive FAT with evidence of foci areas on smears indicating presence of viral antigen-antibody binding as fluorescence apple green (Fig. 2). 


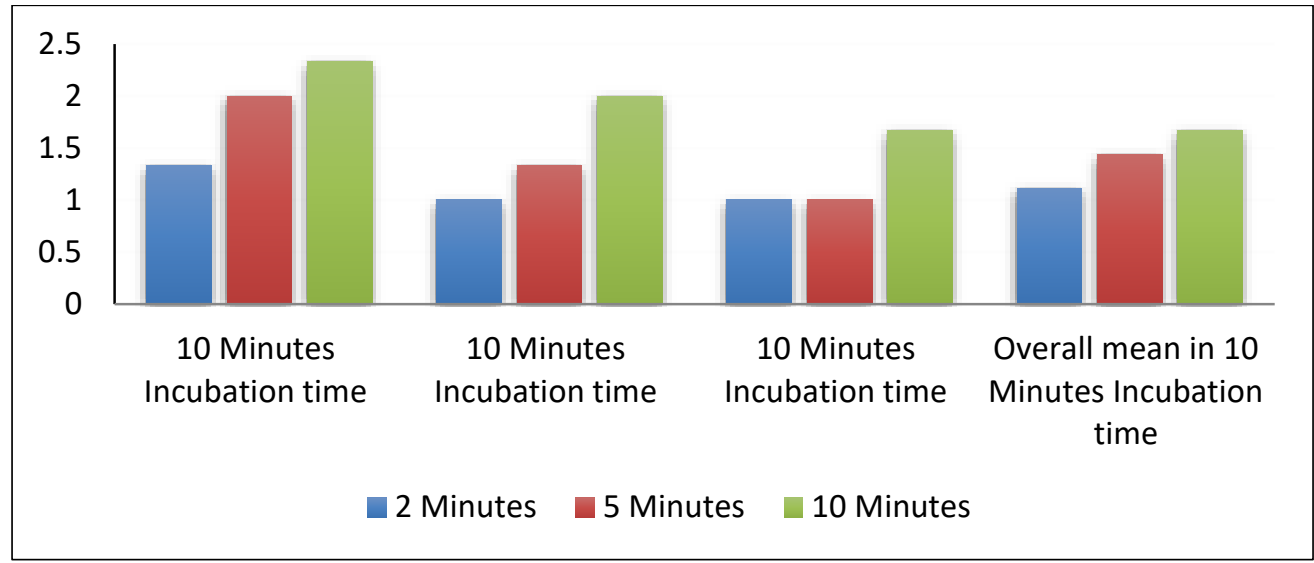

Figure 3: Result of staining grading intensity within Group 1 (incubation at $39^{\circ} \mathrm{C}$ for $10 \mathrm{~min}$ )

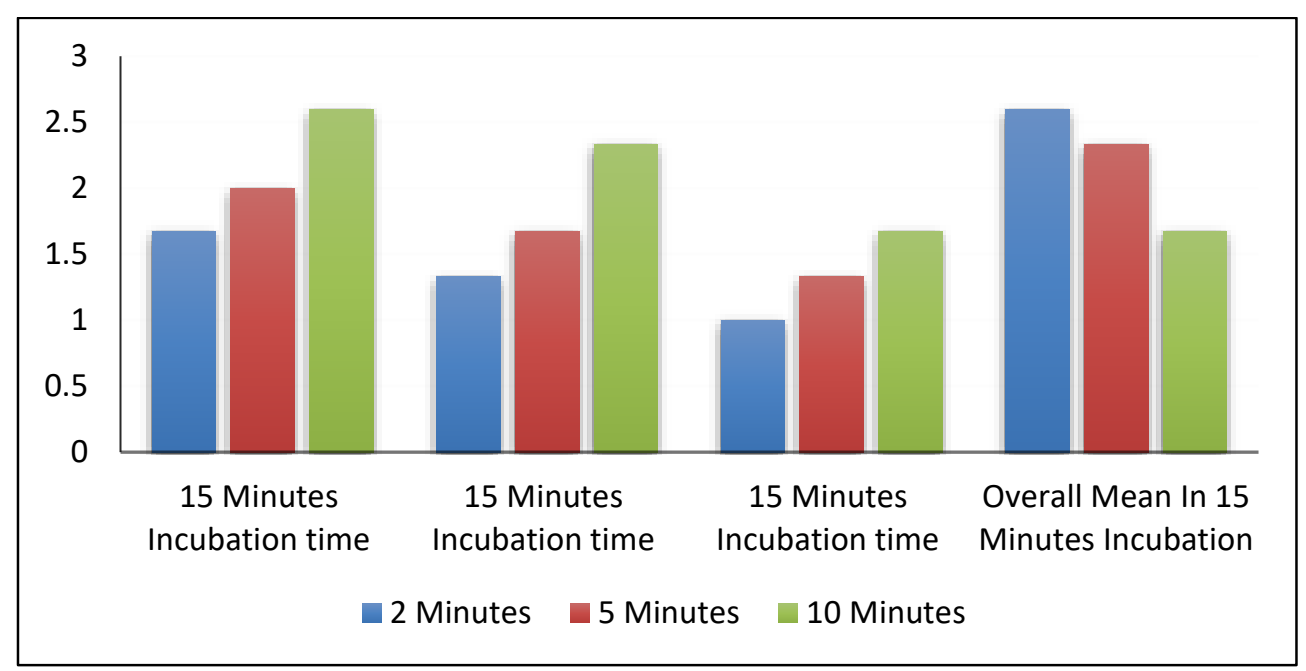

Figure 4: Result of staining grading intensity within Group 2 (incubation at $39{ }^{\circ} \mathrm{C}$ for 15 min)

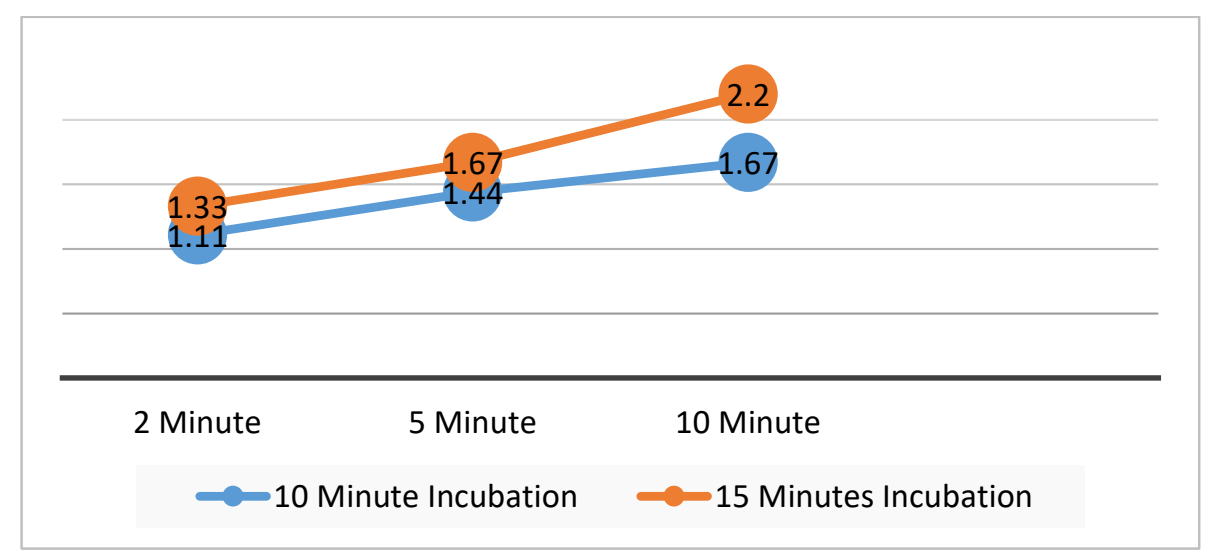

Figure 5: Comparison of staining intensity with different time intervals for FA test

The mean incubation for 10 minutes with different set fixation time is summarized in (Table 2). Fixation time of 2 minute showed the least intensity with $1.11 \pm 0.110$ followed by 5 minutes with $1.44 \pm 0.110$ and 10 minutes with
$1.67 \pm 0.1905$. All groups revealed significant difference of P-value 0.0011, 0.0085, and 0.0141 respectively. 
Second International Virtual Conference of Biotechnology Research Center (IVCBRC-2021) Journal of Biotechnology Research Center

Vol.15 No.2

P-ISSN: 1815-1140

Published Online: (December) 2021 https://doi.org/10.24126/jobrc.2021.15.2.612 $\quad$ E-ISSN: 2708-1370

Table 2: Smear intensity grading in 10 minutes incubation time

\begin{tabular}{|cc|}
\hline Group 1 & Vean $+\mathrm{SE}$ \\
\hline $\mathbf{2}$ Minutes acetone fixation & $\mathbf{1 . 1 1} \pm \mathbf{0 . 1 1 0}$ \\
\hline $\mathbf{1 0}$ Minutes acetone fixation & $\mathbf{1 . 4 4} \pm \mathbf{0 . 2 9 4 2}$ \\
\hline
\end{tabular}

The mean incubation for 15 minutes with different set fixation time is summarized in (Table 3). Fixation time of 2 minute showed the least intensity with $11.33 \pm 0.1934$ followed by 5 minutes with $1.67 \pm 0.1934$ and 10 minutes with $2.20 \pm 0.2762$. All group revealed significant difference between each group with the p-value $0.0031,0.0062$, and 0.045 respectively.

Table 3: Smear intensity grading in 15 minutes incubation time

\begin{tabular}{|cc|}
\hline Group 2 & Mean \pm SE \\
\hline Minutes acetone fixation & $1.33 \pm 0.1934$ \\
\hline 5 Minutes acetone fixation & $1.67 \pm 0.1934$ \\
\hline 10 Minutes acetone fixation & $2.20 \pm 0.2762$ \\
\hline
\end{tabular}

Based on the result revealed in this study and data analysis, it is shown that the results fluctuate with the use of various conjugate dilutions along with different fixation time intervals $(2,5$ and 10

\section{Discussion}

In this study, the have a successful trial and evidence that positive rabies antigen can be detected using direct FA test first. The second attempt was in manipulating the standard protocol for FA test which was conducted and lead to positive presence of various fluorescent staining intensity according to the procedure of manipulation done with various working dilution of FITC (22).

The manipulation conducted from the standard protocol, showed positive intensity of fluorescent staining from the sample tested in all working dilution with different fixation and incubation periods duration time settings (Fig. 5 and 6). This is due to the fact that each sample in this study was impregnated with vaccine in order to obtain virus antigen within the brain tissues for detection using FA test as no positive case sample were obtained during the study. The grade of intensity is not consistent, somewhat varies and lower from the standard protocol depending on the modification of fixation time, conjugate dilution and incubation time similarly reported by (26) in previous attempts of modification.

This study revealed that with modification of 2 minutes acetone fixation and 10 minutes incubation, there is evidence of low staining intensity with +1 in all dilutions indicating stain minutes). Increase in time of fixation, incubation and high concentration of diluent factor will result in increased staining intensity.

is dull with scanty amount of antigen and within $50 \%$ microscope field less particles are observed and interpreted as in Figure 5. Besides that, in 5and 10minutes acetone fixation showed slight increase in stain intensity with some trials within average of +2 and few +3 and with indication of slightly diminished glaring of stain when abundant antigen per field was able to be counted.

In comparison with the standard protocol of 30 minutes acetone fixation with 30 minutes incubation at $37^{\circ} \mathrm{C}$, our study was able to obtain positive outcomes from the modification protocol despite the inconsistent stain intensity due to the presence of rabies virus antigen in the tissue with increase temperature for incubation that generally increases the maximum level of reaction of antigen antibody binding time and multiplication process (6). In addition to that, increase in temperature could result in more rapid reaction of agents that could shorten the time of reaction in normal protocol however the temperature should not exceed $40^{\circ} \mathrm{C}$ as thermal deactivation of organism can occur leading to inaccurate result (27). As for incubation time setting for 15 minutes, evidence of increase staining intensity depending on dilution factors used were observed with high amount +2 and +3 respectively (Figure 6). In comparison with the normal standard OIE 
protocol of FA test, most staining observed in positive cases are within +4 intensity indicating true and high positive value of the antigen present (28).

Based on the results,there is variation in findings that show high concentration of working conjugate and increase in fixation and incubation time that resulted increase in staining intensity thus the grade reaches +2 to +3 with the criteria of dull stain with scanty antigen of one or more particles in few than $100 \%$ held but more in $50 \%$ field $(+2)$, slightly diminished stain with less glare, abundant antigen with more particles per field able to count $(+3)$ compared to OIE gold standard protocol for rabies virus detection obtaining +4 grade. In accordance to the above statement, the technique used in this study is vaccine impregnated tissue resulting in a not genuine or classical case of rabies that might be one of the reasons of unable to obtain high number of +4 staining grade. It is also mainly due to insufficient or no thorough specific working dilution protocol to be used in the DFAT for rabies virus whereby it is usually through try, error and determined by the end user of the experiment conductor (29). Grading of the staining intensity is highly subjective therefore required more than 2 personnel to independently evaluate the slides but the grading was only done by 1 person in this study.

Technical skills are to be highly emphasized in the success rate as it depends largely on how

\section{Conclusion}

In conclusion, the alterations, modification attempts in the standard protocol for FA test in diagnosing rabies antigen resulted in obtaining potential positive results with inconstant and slightly lower grading from the standard OIE protocol. These circumstances highly due to the inadequate time of thorough conduction and

\section{Recommendation}

A more intensive study and wider application of method suggested to obtain more specific and accurate result for a more rapid test to be

\section{Acknowledgments}

The authors are very grateful to the University Malaysia Kelantan, Faculty of Veterinary Medicine, virology Lab and procedures are being carried out with the appropriate preparation especially fluorescent conjugates (FITC) working dilution factors and conduction of the FA test itself (30). Reagents, microscopic examination using fluorescent microscope is commonly advisable to be done with experience personnel in attempts for the test (31).

Although FAT is widely known to be sensitive and specific for detection of rabies, recently new test has been used in several diagnostic laboratories using direct Rapid Immunohistochemical Test dRIT for detection of rabies with similar sensitivity and specificity as per FA test Accordingly, dRIT has been studied to be useful for rapid detection of rabies virus under various circumstances and usage of each diagnostic tool depends on preferences of the personnel and rapidity of the test with accurate result (32-35). It is highly important to ensure the efficacy of each test is well determined and tested on field to be evaluated of its potential.

Presence of positive outcome from the modification of fixation and incubation settings suggests that the DFA test can be modified into a more rapid detecting kit for rabies virus antigen based on the study theory with the significant of the p-value of each group study and further studies can enable the usage and calculate sensitivity and specificity of this modified test and other test such as dRIT.

professional personnel looking into the study. There is no thorough or specific working dilution of the protocol as it is mainly determined by the end user. Grading system used was also subjective and questionable at times therefore further intensive study can be done in future for a more conclusive test.

used in future. Determination of whether the standard protocol for diagnosis of rabies used currently is able to be replaced with a more sensitive and rapid detection test.

molecular biology lab for their provided facilities, which helped to improve the quality of this work. 


\section{Conflict of interests}

The authors declare no conflict of interest.

\section{References}

1. Ananda RA, Ser HL, Letchumanan V. Updates on the development of vaccines and therapeutic options against rabies. Progress in Microbes \& Molecular Biology. (2020) Aug 26; 3(1).

2. Colville J, Berryhill D. Handbook of Zoonoses E-Book: Identification and Prevention. Elsevier Health Sciences. (200); 7: 4.

3. Parker S. A Short History of Medicine. Dorling Kindersley Ltd. (2019); 2.

4. Tantawichien $\mathrm{T}$, Rupprecht CE. Modern biologics for rabies prophylaxis and the elimination of human cases mediated by dogs. Expert Opinion on Biological Therapy. (2020).

5. Centers for Disease Control and Prevention, National Center for Emerging and Zoonotic Infectious Diseases (NCEZID), Division of HighConsequence Pathogens and Pathology (DHCPP)

6. Yang F, Lin S, Ye F, Yang J, Qi J, Chen Z, Lin X, Wang J, Yue D, Cheng $\mathrm{Y}$, Chen Z. Structural analysis of rabies virus glycoprotein reveals $\mathrm{pH}$ dependent conformational changes and interactions with a neutralizing antibody. Cell Host \& Microbe. (2020); 30.

7. Centers for Disease Control and Prevention, National Center for Emerging and Zoonotic Infectious Diseases (NCEZID), Division of HighConsequence Pathogens and Pathology (DHCPP)

8. Ganesan J, Sinniah M, (Occurrence of human rabies in Peninsular Malaysia. Medical Journal of Malaysia. (1993); 48(2): 194-199.

9. Faizul $\mathrm{F}$,Syamsiah A, Rosilina $\mathrm{H}$, Norazura A, Ahmad Fikri A, Syamsul $\mathrm{N}$, Faizal H. Phylogentic analysis of rabies viruses detected in Malaysia. Malaysia journal of Veterinary research. (2019); 10 (2): 32-38.

10. Krauss H, Weber A, Appel M, Enders B, Isenberg HD, Schiefer HG, Slenczka W, von Graevenitz A, Zahner H. Zoonoses: infectious diseases transmissible from animals to humans. Washington, DC: ASM press. (2003).

11. Heydarabadi FH, Baessi $\mathrm{K}$, Bashar R, Fazeli M, Sheikholeslami F. A phylogenetic study of new rabies virus strains in different regions of Iran. Virus Genes. (2020); 56(3):361-368.

12. Fenner FJ, Bachmann PA, Gibbs EPJ. Veterinary Virology. (2014). Academic Press.

13. Wilde H. Rabies. (1996). International Journal of Infectious Diseases. (1997) Jan 1; 1(3): 135-142.

14. Banyard AC, Fooks AR. Rabies Life Cycle, Transmission and Pathogenesis. In Rabies and Rabies Vaccines (2020) (pp. 1-10). Springer, Cham.

15. World Health Organization. WHO expert consultation on rabies: third report. World Health Organization. (2018); 31.

16. Ma X, Monroe BP, Cleaton JM, Orciari LA, Gigante CM, Kirby JD, Chipman RB, Fehlner-Gardiner C, Gutiérrez Cedillo V, Petersen BW, Olson V. Public Veterinary Medicine: Public Health: Rabies surveillance in the United States during 2018. Journal of the American Veterinary Medical Association. (2020); 256(2): 195-208.

17. Poleszak J, Szabat P, Szabat M, Wójcik M, Boreński G, Milanowska J. Neurological symptoms in infectious diseases. Journal of Education, Health and Sport. (2019) Sep 22; 9(9): 930945.

18. Beutner EH. Immunofluorescent staining: the fluorescent antibody method. Bacteriological reviews. (1961); 25(1): 49.

19. Almeida JD. Manual for rapid laboratory viral diagnosis. Geneva, 
Switzerland. (1979).

20. Rao JV. Chapter-1 Rabies: Etiology, Genetic Organization and Comparison of Diagnostic Methods. Advances in. (2020): 1.

21. Fooks AR, Johnson N, Freuling CM, Wakeley PR, Banyard AC, McElhinney LM, Marston DA, Dastjerdi A, Wright E, Weiss RA, Müller T. Emerging technologies for the detection of rabies virus: challenges and hopes in the $21 \mathrm{st}$ century. PLoS Negl Trop Dis. (2009); 3(9): e530.

22. Heydarabadi FH, Baessi K, Bashar R, Fazeli M, Sheikholeslami F. A phylogenetic study of new rabies virus strains in different regions of Iran. Virus Genes. (2020); 56(3): 361-368.

23. Bourhy H, Sureau P. Laboratory methods for rabies diagnosis. Institut Pasteur. (1990).

24. Warner CK, Whitfield SG, Fekadu M, Ho H. Procedures for reproducible detection of rabies virus antigen mRNA and genome in situ in formalin-fixed tissues. Journal of virological methods. (1997); 1: 67(1): 5-12.

25. OIE. 2018 OIE Terrestrial Manual OIE Rabies Availablefrom : (2018)

26. Abdullah MS, Naji MM. Case report: The First Diagnosis of Rabies in Iraq by using Direct Immunofluorescence Antibody Test. The Iraqi Journal of Veterinary Medicine. (2013); 37(2): 294-297.

27. Larghi OP, Ch EJ. Methods for accelerating the fluorescent-antibody test for rabies diagnosis. Applied microbiology. (1971); 1: 21(4): 611613.

28. Voet D, Voet JG, Pratt CW.
Fundamentals of Biochemistry, 1999. John Willey \& Inc.Sons,

29. Dean DJ. The fluorescent antibody tests. Laboratory techniques in rabies. (1996).

30. Fischbach FT, Dunning MB. A manual of laboratory and diagnostic tests. Lippincott Williams \& Wilkins. (2009).

31. Lembo $\mathrm{T}$, Niezgoda $\mathrm{M}$, Velasco-Villa A, Cleaveland S, Ernest E, Rupprecht CE. Evaluation of a direct, rapid immunohistochemical test for rabies diagnosis. Emerging infectious diseases. (2006); 12(2): 310-313.

32. Ehizibolo DO, Nwosuh CI, Ehizibolo EE, Kia GS. Comparison of the Fluorescent Antibody Test and Direct Microscopic Examination for Rabies Diagnosis at the National Veterinary Research Institute, Vom, Nigeria. African Journal of Biomedical Research. (2009); 12(1): 73-76.

33. Mshelbwala PP, Abdullahi SU, Maikai BV, Onyiche ET, Ogunkoya AB. Evaluation of two rapid diagnostic tests for rabies diagnosis under field and laboratory conditions in Nigeria. $\mathrm{J}$ Vaccines Vaccin. (2015); 6(272): 2.

34. Ehizibolo DO, Ogunsan EA, Muhammad MJ, Nwosuh CI, Olaleye S, Chuckwu OO, Sugun MY, Sati NM, Waziri NE, Egwu OK, Kamani J. Diagnosis of canine rabies by the direct fluorescent antibody technique in Plateau state, Nigeria. Nigerian Veterinary Journal. (2008); 29(2): 2024.

35. Rupprecht C, Kuzmin I, Meslin F. Lyssaviruses and rabies: current conundrums, concerns, contradictions and controversies. F1000Research. (2017) ;6. 
Vol.15 No.2

محاولات التحوير باختبار الاجسام المضادة القلورية المياشرة للكثف عن مستضد فايروس داء الكلب في دماغ الفأر

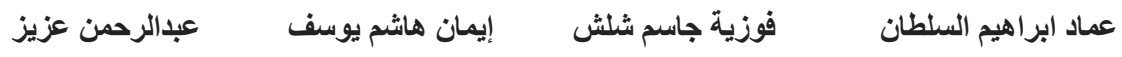

رئيس قسم الباتولوجي / كلية الطب / جامعة لنكولن / ماليزيا

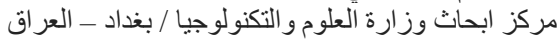

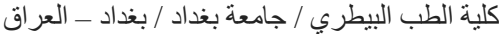
كلية الطب البيطري / جامعة كلينتان / ماليزيا

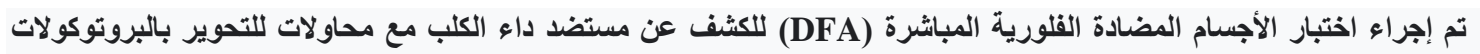

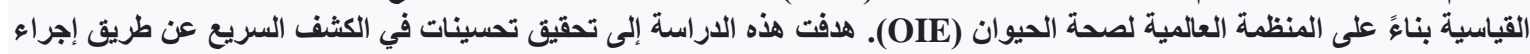

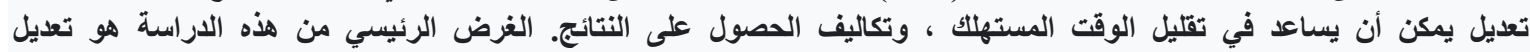

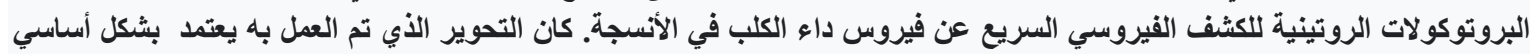

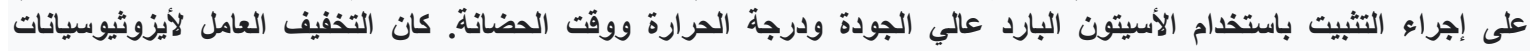

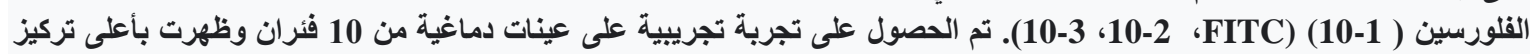

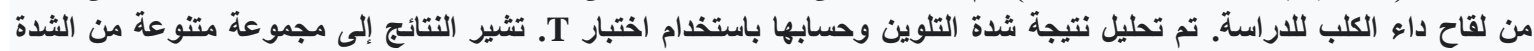
لتلطيخ وتصنيف الفلورسنت بناءً على البروتوكول الذي تم تلثئ التحوير لله. 